\title{
The effectiveness of preliminary traction in the treatment of congenital dislocation of the hip
}

\author{
Pasquale Farsetti ${ }^{*} \mathbb{0}$, Kristian Efremov, Alessandro Caterini, Martina Marsiolo, Fernando De Maio and \\ Ernesto Ippolito
}

\begin{abstract}
Background: Historical papers on the treatment of congenital dislocation of the hip suggest the use of preliminary traction to facilitate closed reduction or to decrease the risk of avascular necrosis (AVN) of the femoral head. In the 1980s, some authors questioned the role of preliminary traction and suspended its use, yielding satisfactory results. Since then, several studies called into question this method, and some authors have continued to recommend preliminary traction while other authors have discouraged its use.

Materials and methods: We reanalysed the full set of radiographs of 71 hips (52 patients) surgically treated by a medial approach after 4 weeks of preoperative longitudinal traction. The mean age at operation was 16 months. Before and after traction, the height of the dislocation was graded according to the Gage and Winter method. The hips were divided into two groups: group 1, in which the traction was effective, and group 2, in which the traction was not effective. These two groups were statistically analysed regarding the severity of the dislocation, the age of the patient at surgery and the incidence of AVN.

Results: Preliminary traction was effective in 48 hips (68\%, group 1), while it was not effective in the remaining 23 ( $32 \%$, group 2). The effectiveness of preliminary traction was statistically related to the height of the dislocation and to the age of the patient at surgery, with traction being less effective in more severe dislocations and in older children. The incidence of AVN was statistically lower in group 1 than in group 2.

Conclusions: In our study population, despite not having a control group, preliminary traction — when effectiveseemed to reduce the incidence of AVN in patients surgically treated for congenital dislocation of the hip. The effectiveness of the traction was influenced by the severity of the dislocation and the age of the patient; it worked better for less severe dislocations and in younger children. To reduce hospital costs, traction should be applied at home.
\end{abstract}

Level of evidence: 3.

Keywords: Developmental dislocation of the hip (DDH), Congenital dislocation of the hip (CDH), Preliminary traction, Avascular necrosis (AVN)

*Correspondence: farsetti@uniroma2.it

Department of Clinical Science and Translational Medicine, Section of Orthopaedics and Traumatology, University of Rome "Tor Vergata", Rome, Italy

\begin{abstract}
Introduction
Developmental dysplasia of the hip (DDH) is an important topic in paediatric orthopaedics [1, 2]. In DDH, the femoral head and acetabulum are misaligned, and the goal of treatment is to obtain a stable concentrically reduced hip joint as soon as possible. Early diagnosis and treatment are crucial to obtaining better results and
\end{abstract}


avoiding surgical procedures [3-5]. An abduction brace is the standard treatment for children younger than 6 months, with a success rate of greater than $90 \%[6,7]$. However, in some cases, conservative treatment fails or the diagnosis is delayed and a hip subluxation or dislocation occurs. In those cases, closed reduction under general anaesthesia or open reduction is indicated [3, 8-10]. The use of preliminary traction to facilitate closed reduction or to decrease the risk of avascular necrosis (AVN) is still debated [11-13]. In the 1980s, some authors questioned the role of preliminary traction in the treatment of congenital dislocation of the hip ( $\mathrm{CDH})$ and suspended its use, reporting satisfactory results in patients treated for $\mathrm{CDH}$ without preliminary traction, with a low incidence of AVN $[14,15]$. Since then, there has been no unanimous consensus on the use of preliminary traction [16-23]. The aim of the present study was to determine the real efficacy of traction in pulling down the dislocated hip, and to report the effectiveness of preliminary traction at decreasing the incidence of AVN in a series of children 3-36 months old who were surgically treated for $\mathrm{CDH}$ by the medial approach.

\section{Materials and methods}

In 2015 we published an article reporting the long-term follow-up for a series of 71 hips (52 patients) surgically treated by a medial approach after 4 weeks of preoperative traction [24]. We reanalysed the full set of radiographs for every patient from diagnosis to follow-up. All patients were put in traction before surgical reduction for 4 weeks. Bilateral cases were treated in two consecutive stages because our traction system does not allow simultaneous traction on both limbs. Before and after traction, the height of the dislocation was graded according to the Gage and Winter method [25]. The authors described four stations to identify the height of dislocation of the proximal femoral epiphysis (the minus-one, zero, plusone and plus-two stations). The medial corner of the metaphysis and the nucleus of the femoral head, when it was present, represented the reference points. At the minus-one station, the medial corner of the metaphysis was superior to the Hilgenreiner line; at the zero station, the medial corner of the metaphysis was at the level of the triradiate cartilage; at the plus-one station, the medial corner of the metaphysis was below the Hilgenreiner line as well as the centre of the capital epiphysis (normal hip); at the plus-two station, the capital epiphysis was below the normal hip.

Regarding the application of traction, we adopted the method described by Lehman et al. [26], who proposed a longitudinal traction system, in order to obtain effective traction and better verify its efficacy through radiographic monitoring. We applied a hip spica cast to the contralateral side to anchor the child to the bed, avoiding progressive sliding of the patient downwards. The child was anchored to the bed by means of two strings passing through two rings incorporated into the cast. Skin traction of one-sixth of the patient's weight was applied to the dislocated hip, and the weight was gradually increased to a maximum of two-thirds of the body weight, according to the staged radiographic monitoring (Fig. 1). The direction of traction was about $20^{\circ}$ of flexion and $20^{\circ}$ of abduction. All the children were checked every day, both in the hospital and at home, by an orthopaedist on our staff or by a senior resident, to clinically monitor the patients, the traction system. Moreover, in the hospital, the nurses were in charge of taking care of the children; at home, the traction system was monitored by the parents, who were in telephone contact with our residents in case of any problems. The effectiveness of the traction was verified by once-weekly radiographic examination of the pelvis in bed. Traction was considered to be effective when the femoral metaphysis was pulled down to the plus-one or plus-two station. Traction was always stopped at the end of the 4th week. To reduce hospital costs, traction was applied and maintained at home in about half of our patients. The real effectiveness of traction at pulling down the dislocated hip was radiographically evaluated according to the Gage and Winter method, and the hips were divided into two groups: group 1 , in which the traction was effective (Fig. 2), and group 2, in which the traction was not effective (Fig. 3). These two groups were statistically analysed regarding the initial severity of the dislocation, the age of the patient at surgery, and the incidence of AVN of the proximal femoral epiphysis according to the classification of Bucholz and Ogden [27] as modified by Morcuende et al. [4].

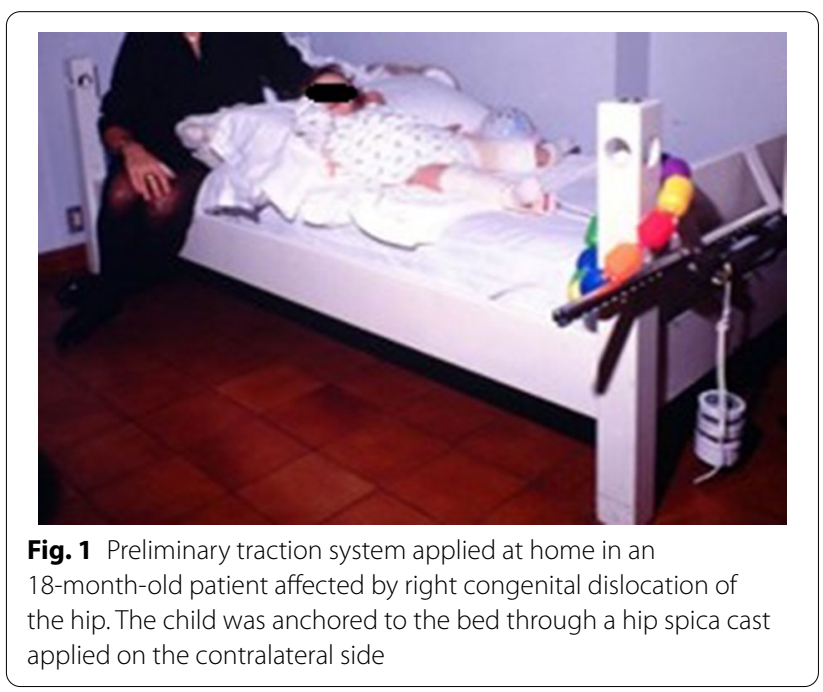




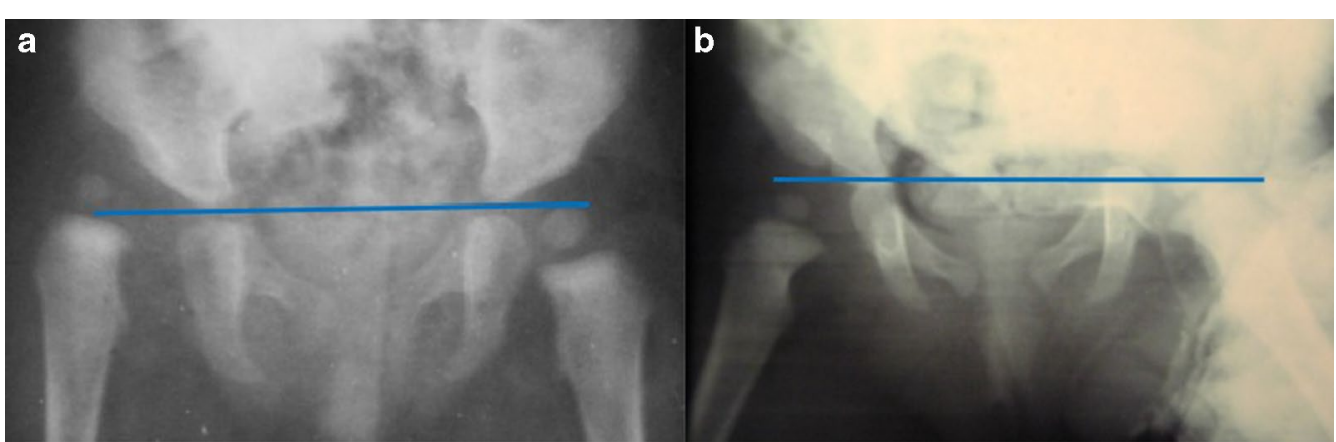

Fig. 2 Radiographic examination of congenital dislocation of the right hip in a 14-month-old child before starting treatment by preliminary traction. The affected hip was classified as being at the minus-one station according to the Gage and Winter method (a). After 4 weeks, X-ray showed the effectiveness of the traction, as it had pulled the femoral head down to the plus-one station (group 1) (b)

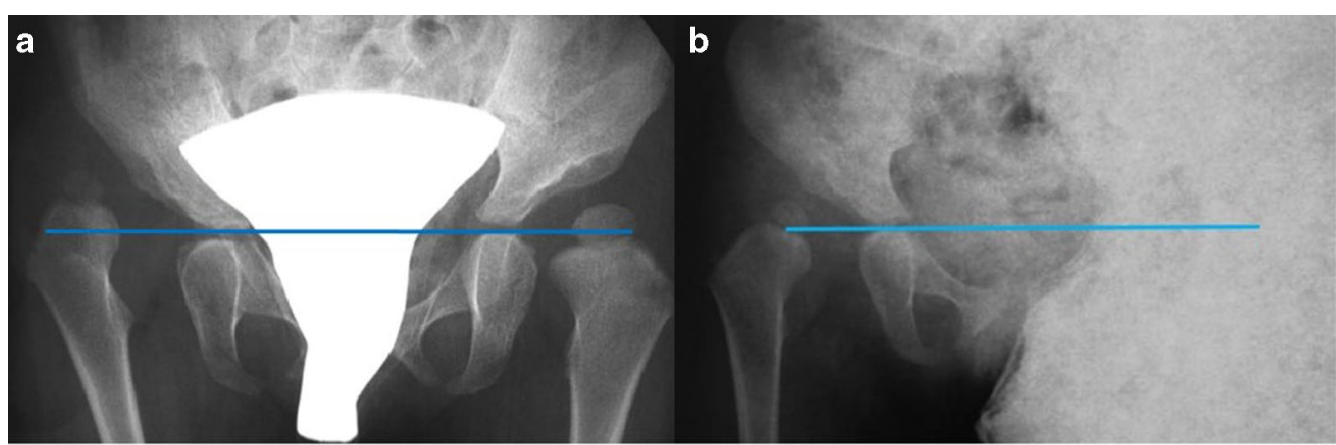

Fig. 3 Radiographic examination of congenital dislocation of the right hip in a 30-month-old child before starting treatment by preliminary traction. The affected hip was classified as being at the minus-one station according to the Gage and Winter method (a). After 4 weeks, X-ray showed that the femoral head was at the zero station, so the traction was considered to be ineffective (group 2) (b)

All methods were carried out in accordance with relevant guidelines and regulations.

Fisher's exact test was used to evaluate the significance of differences in the severity of dislocation, patient age and incidence of AVN between the two groups. All statistical analyses were performed using the SigmaStat (version 3.1) program (Systat Software). A $p$ value $<0.05$ was considered significant.

\section{Results}

There were 71 hips (52 patients). Age at operation ranged from 3 to 36 months, with an average age of 16 months; 42 patients were female and 10 were male. The left hip was dislocated in 40 cases and the right in 31; 25 patients had bilateral dislocation, but closed reduction of one dislocated hip was successful in six of those patients (Table 1).

Before surgery, according to the Gage and Winter method, 57 hips were classified as being at the minusone station while 14 hips were at the zero station. Among the patients who had hips at the minus-one station, 16 patients were aged less than 1 year, 15 were aged between
Table 1 Demographic characteristics and clinical features of the patients and hips

\begin{tabular}{ll}
\hline $\begin{array}{l}\text { Total number of hips (patients) } \\
\text { Average age at surgery (range of age at surgery) }\end{array}$ & $\begin{array}{l}71 \text { (52) } \\
16 \text { months } \\
\text { (3-36 months) }\end{array}$ \\
$\begin{array}{l}\text { Sex } \\
\text { Female }\end{array}$ & 42 patients \\
Male & 10 patients \\
Side & \\
Left & 40 hips \\
Right & 31 hips \\
Unilateral & 33 patients \\
Bilateral requiring surgery on both sides & 19 patients \\
Bilateral requiring surgery on one side only & 6 patients
\end{tabular}

1 and 2 years and 11 were aged more than 2 years. Among the patients who had hips at the zero station, 6 patients were aged less than 1 year and 4 were aged between 1 and 2 years; none were aged more than 2 years. Preliminary traction was effective in 48 hips (68\%, group 1), while it 
was not effective in the remaining 23 (32\%, group 2). The results for groups 1 and 2 and the statistical differences between them are reported in Table 2 .

Among the 48 hips in which traction was effective (group 1), we observed five cases of AVN (three type II and two type IV). Among the 23 hips in which preliminary traction was ineffective (group 2), we observed eight cases of AVN (one type II, one type III, five type IV and one type $\mathrm{V}$ ). The effectiveness of preliminary traction was statistically related to the lower incidence of AVN in group 1 compared to group $2(p=0.02)$.

We did not observe any difference in terms of final results between patients treated by traction in hospital and patients treated by traction at home.

\section{Discussion}

The effectiveness of preliminary traction in reducing the incidence of AVN after closed or open reduction in CDH is still controversial. In 1972, Gage and Winter [25] reported that adequate traction reduced the incidence of AVN in a series of 154 cases of CDH treated with and without preliminary traction. In the same article, they proposed a classification method to assess the level of dislocation of the femoral head in order to evaluate the effectiveness of the traction. In 1979, Weinstein and Ponseti [14] reported that satisfactory results were obtained without using preliminary traction, including a low rate of AVN. Some years later, other authors [15, 28] agreed that prereduction traction was not useful; they reported that good results were achieved without preliminary traction and recommended abandoning this procedure. According to those authors, patients with $\mathrm{CDH}$ were safety treated with either closed or open reduction without preliminary traction. At the same time, Fish et al. [16] published a survey of 335 POSNA members regarding this issue. Most responders believed that traction reduced the incidence of AVN and enabled easier reduction; only $5 \%$ of those surveyed did not use preliminary traction; 31\% were in favour of applying the traction at home, prolonging the traction time but reducing hospital costs.

During the subsequent decade, the authors of two different studies noted the utility of preliminary traction, including in older children [29,30]. They used overhead traction in which the hip was flexed at about $100^{\circ}$ and abducted at $20^{\circ}$. Those authors reaffirmed that overhead traction successfully achieved closed reduction in a high percentage of dislocated hips with a low incidence of AVN, including untreated congenitally dislocated hips in children 18-71 months old. They encouraged other orthopaedic surgeons to seriously consider the clinical utility of preliminary traction when treating $\mathrm{CDH}$. On the contrary, at the same time, other authors did not find any benefits of preliminary traction in respect to increasing the possibility of closed reduction and reducing the incidence of AVN $[17,18]$. They stated that "it cannot be proven that traction alters the outcome of developmental dislocation of the hip treatment, and hence there is only an anecdotal basis of its use" [18].

More recently, some authors have continued to recommend preliminary traction [11, 20-23, 31, 32]. Langenskiold et al. [20] compared two large series of patients with DDH treated with and without preliminary traction. They concluded that prereduction traction decreases the incidence of AVN of the femoral head in children aged 6-36 months and that traction represented the only difference between the two groups. In subsequent studies, other authors have reiterated the important role of prolonged preliminary traction with different methods to minimize the risk of AVN [11, 21, 23]. Park et al. [31], in a recent systematic review, concluded that "although there is a

Table 2 Results for group 1 (in which traction was effective) and group 2 (in which traction was not effective)

\begin{tabular}{lll}
\hline & $\begin{array}{l}\text { Group 1 } \\
\text { Effective traction }\end{array}$ & $\begin{array}{l}\text { Group 2 } \\
\text { Ineffective traction }\end{array}$ \\
\hline $\begin{array}{l}\text { Total number of hips (number of patients) } \\
\text { Height of dislocation }\end{array}$ & $48(37)$ & $23(15)$ \\
$\begin{array}{l}\text { Minus-one station } \\
\text { Zero station }\end{array}$ & 34 & 23 \\
Age distribution of patients at surgery & 14 & 0 \\
Patients $<1$ years old (no. of hips) & $22(26)$ & \\
Patents 1-2 years old (no. of hips) & $15(22)$ & $0(0)$ \\
Patients $>2$ years old (no. of hips) & $0(0)$ & $4(5)$ \\
AVN & 5 hips (10\%) & $11(18)$ \\
\hline
\end{tabular}

$p$ value $<0.05$ was considered significant

The height of dislocation was evaluated according to the Gage and Winter method 
trend toward a decreasing use of traction, prereduction traction remains as a treatment tradition or a gesture toward medico-legal environment". In the same year, Wicart et al. [32] reported a literature review evaluating the published results and complications of closed reduction in late-detected DDH. The authors concluded that the Petit-Morel method was the treatment of choice for children aged between 6 months and 3 years who were affected by idiopathic DDH. On the contrary, other authors in three different comparative studies that included a large series of dislocated hips reported that preliminary traction (overhead or longitudinal) did not decrease the failure of reduction or the incidence of AVN $[12,13,19]$. Schur et al. [33] even reported an increased risk of AVN when prereduction traction was used in a series of 70 children ( 82 hips).

The results reported by all the articles cited above are summarized in Table 3.

To the best of our knowledge, the real effectiveness of preliminary traction, defined as the ability to pull the femoral head below the level of the triradiate cartilage, has never been radiographically assessed. In our study, we have verified, by radiographic monitoring, the real effectiveness of the traction in a series of 71 hips. In our patients, traction was effective in $68 \%$ of cases, while it was not effective in the remaining $32 \%$. In the latter cases, the dislocations were more severe (femoral head at the minus-one station according to the Gage and

Table 3 Summary of literature data on the use of preliminary traction in the treatment of congenital dislocation of the hip

\begin{tabular}{|c|c|c|c|c|c|c|}
\hline Authors & $\begin{array}{l}\text { Journal, year of } \\
\text { publication }\end{array}$ & $\begin{array}{l}\text { Number of hips } \\
\text { (traction vs no } \\
\text { traction) }\end{array}$ & $\begin{array}{l}\text { Use of } \\
\text { preliminary } \\
\text { traction }\end{array}$ & $\begin{array}{l}\text { Incidence of AVN } \\
(\%)\end{array}$ & $\begin{array}{l}\text { Length of } \\
\text { follow-up }\end{array}$ & $\begin{array}{l}\text { Recommendations } \\
\text { for traction use }\end{array}$ \\
\hline $\begin{array}{l}\text { Weinstein, Ponseti } \\
\text { (lowa, USA) [14] }\end{array}$ & JBJS Am, 1979 & 10 vs 12 hips & Comparative & $10 \%$ vs $10 \%$ & $3.5 \mathrm{y}$ & Not recommended \\
\hline $\begin{array}{l}\text { Kahle et al. (Utah, } \\
\text { USA) [28] }\end{array}$ & JBJS Am, 1990 & 47 hips & No & $3.5 \%$ & $>2 y$ & Not recommended \\
\hline $\begin{array}{l}\text { Fish et al. (Michigan, } \\
\text { USA) [16] }\end{array}$ & JPO, 1991 & Survey (POSNA) & Comparative & Not reported & Not reported & Recommended \\
\hline $\begin{array}{l}\text { Tavares et al. (lowa, } \\
\text { USA) [29] }\end{array}$ & JPO, 1994 & 27 hips & Yes & $7.4 \%$ & Not reported & Recommended \\
\hline $\begin{array}{l}\text { Quinn et al. (Con- } \\
\text { necticut, USA) [17] }\end{array}$ & JPO, 1994 & 75 hips & Yes & $6.7 \%$ & $5.4 y$ & Not recommended \\
\hline $\begin{array}{l}\text { Daoud et al. (Algeria) } \\
\text { [30] }\end{array}$ & JBJS Am, 1996 & 50 hips & Yes & $10 \%$ & $4 y$ & Recommended \\
\hline $\begin{array}{l}\text { Weinstein (lowa, } \\
\text { USA) [18] }\end{array}$ & CORR, 1997 & Update & No & Not reported & Not reported & Not recommended \\
\hline $\begin{array}{l}\text { Langenskiold et al. } \\
\text { (Finland) [20] }\end{array}$ & $J P O, 2000$ & 176 vs 86 hips & Comparative & $2.8 \%$ vs $46.5 \%$ & 13.1 y & Recommended \\
\hline $\begin{array}{l}\text { Kutlu et al. (Turkey) } \\
\text { [19] }\end{array}$ & $J P O, 2000$ & 89 vs 65 hips & Comparative & $4.5 \%$ vs $0 \%$ & 5 y vs $2.5 y$ & Not recommended \\
\hline $\begin{array}{l}\text { Yamada et al. (Japan) } \\
\text { [21] }\end{array}$ & JBJS Br, 2003 & 62 hips & Yes & $1.6 \%$ & $>2 y$ & Recommended \\
\hline $\begin{array}{l}\text { Sibinski et al. } \\
\text { (Poland) [22] }\end{array}$ & Int Orthop, 2006 & 107 vs 48 hips & Comparative & $1.9 \%$ vs $14.6 \%$ & $19.5 y$ & Recommended \\
\hline $\begin{array}{l}\text { Rampal et al. (France) } \\
\text { [23] }\end{array}$ & JBJS Br, 2008 & 47 hips & Yes & $2.1 \%$ & $14.3 y$ & Recommended \\
\hline $\begin{array}{l}\text { Terjesen et al. (Nor- } \\
\text { way) [1 1] }\end{array}$ & JBJS Am, 2014 & 90 hips & Yes & $10 \%$ & $51.6 y$ & Recommended \\
\hline $\begin{array}{l}\text { Schur et al. (Califor- } \\
\text { nia, USA) [33] }\end{array}$ & J Child Orthop, 2016 & 70 hips & Yes & $35 \%$ & $5 y$ & Not recommended \\
\hline $\begin{array}{l}\text { Sucato et al. (Texas, } \\
\text { USA) [12] }\end{array}$ & JPO, 2017 & 276 vs 66 hips & Comparative & $18 \%$ vs $8 \%$ & $10.4 y$ & Not recommended \\
\hline Park et al. (Korea) [31] & $\begin{array}{l}\text { Ther Clin Risk Manag, } \\
2018\end{array}$ & $\begin{array}{l}\text { Systematic review } \\
\text { (683 hips) }\end{array}$ & Comparative & $5-47 \%$ vs $0-72 \%$ & Not reported & Not recommended \\
\hline $\begin{array}{l}\text { Wicart et al. (France) } \\
\text { [32] }\end{array}$ & J Child Orthop, 2018 & Review & Yes & $2 \%$ to $72 \%$ & Not reported & Recommended \\
\hline Li et al. (China) [13] & JPO B, 2019 & $\begin{array}{l}\text { Systematic review } \\
\text { (440 hips) }\end{array}$ & Comparative & $14 \%$ vs $14.5 \%$ & $3.1 \mathrm{y}$ & Not recommended \\
\hline
\end{tabular}


Winter method) and the mean age of the children was higher; moreover, in this group of patients (group 2), we observed a statistically significantly greater incidence of AVN than in the group of patients for whom traction was effective (group 1). Therefore, we believe that the real effectiveness of traction itself should be verified before stating a definitive opinion on the real benefit in terms of decreasing AVN.

In the cases in which traction was not effective, we speculate that soft tissues were stiffer and muscles were more contracted than in the cases in which traction was effective. In the cases in which traction was not effective, femoral shortening osteotomy could be considered as a means to further reduce the AVN rate [34]. The reason for this may be that the dislocation was radiographically more severe in the majority of our cases in which traction was not effective, and the mean age of those patients was higher, regardless of whether the patient was treated in the hospital or at home. It is well known that muscle contraction is directly proportional to the extent of muscle lengthening and increases over time.

We agree with other authors [18] about the difficulty of radiographically assessing the effectiveness of overhead traction with the hip flexed at $90^{\circ}$. In our cases, we applied longitudinal traction with the hip flexed at $20^{\circ}$, so radiographic images were easily taken.

In our opinion, the length of traction time is another important factor to consider. In accordance with other authors, we believe that traction must be continued for at least 4 weeks to be effective $[11,21]$.

Finally, to reduce hospital costs, traction should be applied at home, as done in about half of our patients. We believe that, when compared to overhead traction, longitudinal traction is more easily managed at home, so we recommend a traction method that keeps the hip slightly flexed [26].

\section{Conclusions}

According to the results for our study population, preliminary traction seems to reduce the incidence of AVN in patients surgically treated for congenital dislocation of the hip. However, our conclusions will need to be confirmed by further studies involving a control group of patients treated without preliminary traction. To evaluate the real effectiveness of traction, we support the use of longitudinal traction, which allows easy radiographic monitoring that can be performed at home, reducing hospital costs. The effectiveness of the traction is influenced by the severity of the dislocation and the age of the patient; it works better with less severe dislocations and in younger children.
Acknowledgements

Not applicable.

\section{Authors' contributions}

Conceptualization: PF, El. Data collection: AC, KE, MM. Data analysis: PF, FDM. Draft: PF, AC, KE. Review and editing: PF, El. All authors read and approved the final manuscript.

\section{Funding}

No funding was obtained for this study.

\section{Availability of data and materials}

The data used and analysed during the current study are available from the corresponding author on reasonable request.

\section{Declarations}

Ethics approval and consent to participate

This study was approved by the Ethical Committee of the Policlinico di Tor Vergata, Rome, Italy. Informed consent was obtained from all patients or from a parent or legal guardian for underage patients.

\section{Consent for publication}

Not applicable.

\section{Competing interests}

The authors declare that they have no competing interests.

Received: 18 December 2020 Accepted: 3 June 2021

Published online: 27 June 2021

\section{References}

1. Woodacre T, Ball T, Cox P (2016) Epidemiology of developmental dysplasia of the hip within the UK: refining the risk factors. J Child Orthop 10:633-642

2. Pollet V, Percy V, Prior HJ (2017) Relative risk and incidence for developmental dysplasia of the hip. J Pediatr 181:202-207

3. Cordier W, Tönnis D, Kalchschmidt K, Storch KJ, Katthagen BD (2005) Long-term results after open reduction of developmental hip dislocation by an anterior approach lateral and medial of the iliopsoas muscle. J Pediatr Orthop B 14(2):79-87

4. Morcuende JA, Meyer MD, Dolan LA, Weinstein SL (1997) Long-term outcome after open reduction through an anteromedial approach for congenital dislocation of the hip. J Bone Joint Surg Am 79:810-817

5. Farsetti P, Caterini R, De Maio F, Potenza V, Efremov K, Ippolito E (2019) Tönnis triple pelvic osteotomy for the management of late residual acetabular dysplasia: mid-term to long-term follow-up study of 54 patients. J Pediatr Orthop B 28:202-206

6. Grill F, Bensahel H, Canadell J, Dungl P, Matasovic T, Vizkelety T (1988) The Pavlik harness in the treatment of congenital dislocating hip: report on a multicenter study of the European Pediatric Orthopaedic Society. J Pediatr Orthop 8:1-8

7. Wahlen R, Zambelli PY (2015) Treatment of the developmental dysplasia of the hip with an abduction brace in children up to 6 months old. Adv Orthop 2015:103580

8. Varner KE, Incavo SJ, Haynes RJ, Dickson JH. Surgical treatment of developmental hip dislocation in children aged 1 to 3 years: a mean 18-year, 9-month follow-up study. Orthopedics. 2010;33(3)

9. Holman J, Carroll KL, Murray KA, Macleod LM, Roach JW (2012) Long-term follow-up of open reduction surgery for developmental dislocation of the hip. J Pediatr Orthop 32(2):121-124

10. Cooper AP, Doddabasappa SN, Mulpuri K (2014) Evidence-based management of developmental dysplasia of the hip. Orthop Clin N Am 45(3):341-354

11. Terjesen T, Horn J, Gunderson RB (2014) Fifty-year follow-up of late detected hip dislocation: clinical and radiographic outcomes for seventyone patients treated with traction to obtain gradual closed reduction. J Bone Joint Surg Am 96(4):e28 
12. Sucato DJ, De La Rocha A, Lau K, Ramo BA (2017) Overhead Bryant's traction does not improve the success of closed reduction or limit AVN in developmental dysplasia of the hip. J Pediatr Orthop 37(2):e108-e113

13. Li YQ, Li M, Guo YM, Shen XT, Mei HB, Chen SY, Shao JF, Tang SP, Canavese F, Xu HW (2019) Traction does not decrease failure of reduction and femoral head avascular necrosis in patients aged 6-24 months with developmental dysplasia of the hip treated by closed reduction: a review of 385 patients and meta-analysis. J Pediatr Orthop B 28(5):436-441

14. Weinstein SL, Ponseti IV (1979) Congenital dislocation of the hip. J Bone Joint Surg 61A:119-124

15. Coleman SS (1987) A critical analysis of the value of preliminary traction in the treatment of $\mathrm{CDH}$. Orthop Trans 13:180

16. Fish DN, Herzenberg JE, Hensinger RN (1991) Current practice in use of prereduction traction for congenital dislocation of the hip. J Pediatr Orthop 11(2):149-153

17. Quinn RH, Renshaw TS, DeLuca PA (1994) Preliminary traction in the treatment of developmental dislocation of the hip. J Pediatr Orthop 14:636-642

18. Weinstein SL (1997) Traction in developmental dislocation of the hip. Is its use justified? Clin Orthop Relat Res 338:79-85

19. Kutlu A, Ayata C, Ogun TC, Kapicioglu MI, Mutlu M (2000) Preliminary traction as a single determinant of avascular necrosis in developmental dislocation of the hip. J Pediatr Orthop 20:579-584

20. Langenskiold A, Paavilainen T (2000) The effect of prereduction traction on the results of closed reduction of developmental dislocation of the hip. J Pediatr Orthop 20:471-474

21. Yamada N, Maeda S, Fujii G, Kita A, Funayama K, Kokubun S (2003) Closed reduction of developmental dislocation of the hip by prolonged traction. J Bone Joint Surg B 85-B:1173-1177

22. Sibinski M, Murnaghan C, Synder M (2006) The value of preliminary overhead traction in the closed management of DDH. Int Orthop 30:268-271

23. Rampal V, Sabourin M, Erdeneshoo E, Koureas G, Seringe R, Wicart P (2008) Closed reduction with traction for developmental dysplasia of the hip in children aged between one and five years. J Bone Joint Surg B 90-B:858-863

24. Farsetti P, Caterini R, Potenza V, Ippolito E (2015) Developmental dislocation of the hip successfully treated by preoperative traction and medial open reduction: a 22-year mean follow-up. Clin Orthop Relat Res 473(8):2658-2669
25. Gage JR, Winter RB (1972) Avascular necrosis of the capital femoral epiphysis as a complication of closed reduction of congenital dislocation of the hip. A critical review of twenty years' experience at Gillette Children's Hospital. J Bone Joint Surg Am 54(2):373-388

26. Lehman WB, Grant AD, Nelson J, Robbins H, Milgram J (1983) Hospital for Joint Diseases' traction system for preliminary treatment of congenital dislocation of the hip. J Pediatr Orthop 3(1):104-107

27. Bucholz RW, Ogden JA (1978) Patterns of ischemic necrosis of the proximal femur in nonoperatively treated congenital hip disease. In: The Hip Society (ed) The Hip: Proceedings of the Sixth Open Scientific Meeting of the Hip Society. CV Mosby, St Louis, pp 43-63

28. Kahle WK, Anderson MB, Alpert J, Stevens P, Coleman SS (1990) The value of preliminary traction in the treatment of congenital dislocation of the hip. J Bone Joint Surg Am 72:1043-1047

29. Tavares JO, Gottwald DH, Rochelle JR (1994) Guided abduction traction in the treatment of congenital hip dislocation. J Pediatr Orthop 14:643-649

30. Daoud A, Saighi-Bououina A (1996) Congenital dislocation of the hip in the older child. The effectiveness of overhead traction. J Bone Joint Surg Am 78:30-40

31. Park KB, Vaidya VN, Shin H, Kwak YH (2018) Prereduction traction for the prevention of avascular necrosis before closed reduction for developmental dysplasia of the hip: a meta-analysis. Ther Clin Risk Manag $14: 1253-1260$

32. Wicart P, Seringe R, Glorion C, Brassac A, Rampal V (2018) Closed reduction in late-detected developmental dysplasia of the hip: indications, results and complications. J Child Orthop 12:317-322

33. Schur MD, Lee C, Arkader A, Catalano A, Choi PD (2016) Risk factors for avascular necrosis after closed reduction for developmental dysplasia of the hip. J Child Orthop 10:185-192

34. Schoenecker PL, Strecker WB (1984) Congenital dislocation of the hip in children: comparison of the effects of femoral shortening and of skeletal traction in treatment. J Bone Joint Surg Am 66:21-27

\section{Publisher's Note}

Springer Nature remains neutral with regard to jurisdictional claims in published maps and institutional affiliations.

\section{Submit your manuscript to a SpringerOpen ${ }^{\circ}$ journal and benefit from:}

- Convenient online submission

- Rigorous peer review

- Open access: articles freely available online

- High visibility within the field

Retaining the copyright to your article

Submit your next manuscript at springeropen.com 